\title{
Studies of the laser etching on painted plastic parts to prevent the risks of engraving failures at mechatronic devices
}

\author{
Ion Cristian Braga ${ }^{1, *}$, Anisor Nedelcu ${ }^{1}$, and Razvan Udroiu $^{1}$ \\ ${ }^{1}$ Transilvania University of Braşov, Department of Manufacturing Engineering, Mihai Viteazu No.5, \\ Braşov, Romania
}

\begin{abstract}
Nowadays, the automotive mechatronic devices are developed with many symbols engraved over the painted plastic parts. Many risks are coming due to painting layer, which could be dry or not, the paint thickness variability it is also one important aspect. The paper's aim is to present the studies of the laser etching process and the risk reduction of the possible failure by using the 2D optical measurement of different parameters for the laser beam, also using the 3D scanning in order to see the deep etching of the paint. The experiments will let the team know what should be the parameter setting for the painted plastic materials delivered in production in different time after the painting, therefore to reduce the over-adjusting and first part approval process duration.
\end{abstract}

\section{Introduction}

The word laser is coming from an acronym, LASER, standing for "Light Amplification by Stimulated Emission of Radiation". History of the laser began in 1916 with the first concept of the stimulated emission published by A. Einstein in the paper "On The Quantum Theory of Radiation" [1]. But the first working LASER was invented by Theodore Maiman who built this in nine months based on the ruby rod from his MASER (predecessor of the LASER, but using microwave instead of light) research, so in $16^{\text {th }}$ of May, 1960 "a trace of red light pulse was registered on a Hughes Memoscope" [2].

There are different types of the laser according to the physical state of view: solid state laser, liquid laser, gas laser, X-Ray laser, chemical laser, excimer laser, fiber hosted laser. The solid state laser could be classified based on an insulator as Ruby Laser, Nd: YAG and Nd: Glass Lasers, Yt: YAG laser, Color Center Laser, Alexandrite Laser, Ti-Saphire Laser, also based on a semiconductor as Gallium Arsenide Laser or Gallium Nitride Laser. The gas laser could be classified based on the atom laser as Helium-Neon or Helium-Cadmium, molecule as $\mathrm{CO}_{2}$ (Carbon Dioxide) or $\mathrm{N}_{2}$ (Nitrogen), ion laser as Argon ion or Krypton ion, and metal vapor laser as Copper Vapor or Gold Vapor. The fiber hosted lasers are based on Erbium and Yttrium ions in double clad forms [3].

\footnotetext{
* Corresponding author: jbc69mc@gmail.com
} 
In automotive industry are often met $\mathrm{CO}_{2}$ gas laser where the main emission wavelengths are $10.6 \mu \mathrm{m}$ and $9.4 \mu \mathrm{m}$, and the $\mathrm{Nd}$ : YAG laser where the main emission wavelength is at $1.064 \mu \mathrm{m}$.

The Nd: YAG is an acronym stands for Neodymium: Yttrium-Aluminium-Garnet and is a rod based on the synthetic crystalline material of garnet with formula $\mathrm{Y}_{3} \mathrm{Al}_{5} \mathrm{O}_{12}$ doped with Neodymium, a rare earth element, and where some $\mathrm{Y}^{3+}$ ions are replaced by the other ions of $\mathrm{Nd}^{3+}$. The primary emission of Nd: YAG wavelength is $1064 \mathrm{~nm}$ [4].

The Nd: YAG laser is optically pumped by a flash tube or laser diodes. In the laser cavity is a Q-switch which control the maximum population inversion of the neodymium ions to generate modulated pulses. The optical resonator consists also in a highly reflective mirror (HR) which amplifies the light and an output mirror (OM) a partially reflective mirror with small hole which reflect the most of all light inside of cavity and let some photons to escape - the beam of the laser (see Figure 1) [5,6].

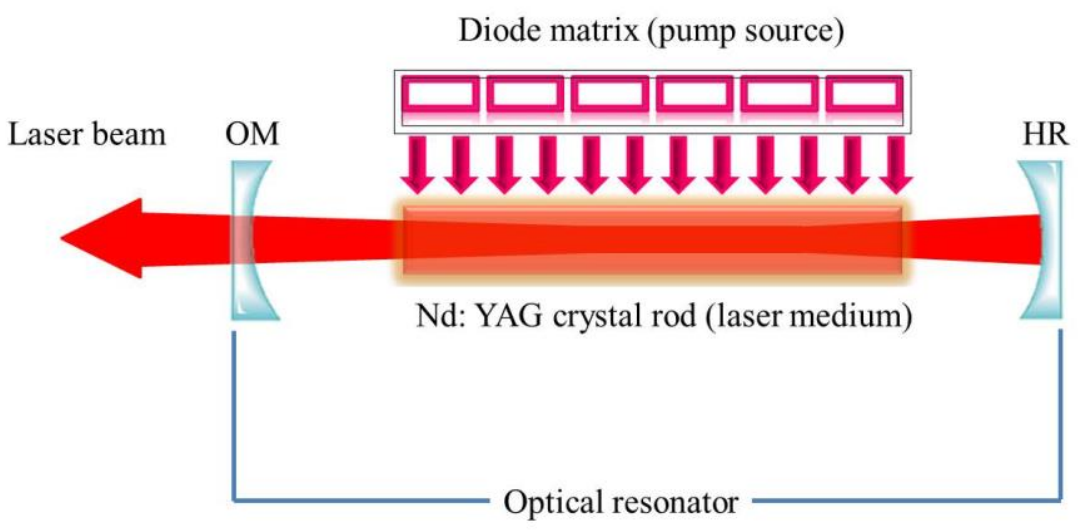

Fig. 1. Schematic diagram of the Nd:YAG laser diode pumped.

The Nd: YAG lasers are often met in the automotive industry and are used for cutting, welding, engraving, marking, etching or ablation. As similar researches in the field are related to the generalities of the using of the Nd:YAG laser for etching, but not for the influence of the parameters over the final result, the aim of this paper is to make the analysis of the $\mathrm{Nd}$ : YAG laser parameter variation at etching painted plastic parts where the drying of the painted parts is variable too.

\section{Case study}

The case study is made in an automotive manufacturer which produces mechatronic devices. As the manufacturing processes, these devices consist of assemblies of electronic, metallic and plastic components. Many of them are used in the interior of the cars and are in the visible area of the driver or the other passengers.

The plastic components from the visible area with different symbols are illuminated by the light behind coming from the electronic components. Therefore, the plastic molded injected parts are mainly white or transparent and painted over the surface. The painting systems are water based, as solvent based too. At the end, the symbols are made by removing the paint by laser etching as is presented in Figure 2, a) and b). 


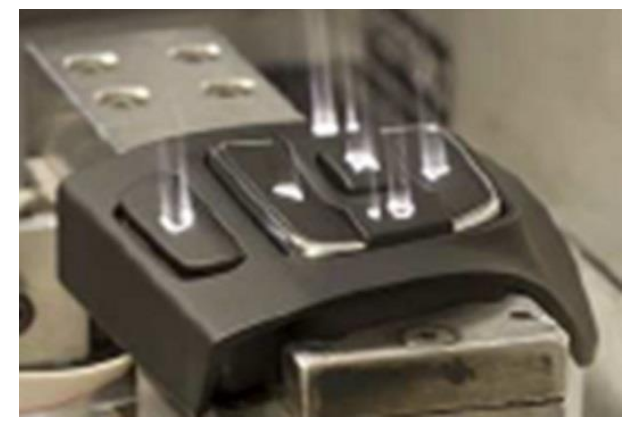

Fig. 2. a) Laser etching of painted plastic parts.

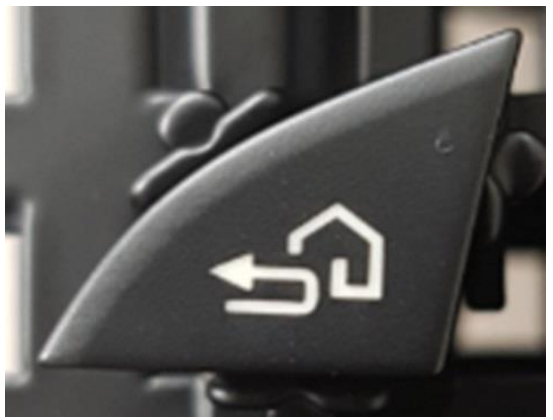

b) Symbol after laser etching.

The aim of the study is to find a correlation between the laser setting parameters and the drying stage of the painted parts, as was known that sometimes the painted parts are delivered to laser etching almost immediately after the end of painting line or even after more than 8 hours. The risk to deliver parts with not good engraved symbols is present, the non-conform parts could be with a symbol not clean (paint residues in the white or transparent areas) or burn material due to the intensity of the laser beam. An adjustment is needed at the change of the batch as every program for each dedicated project part number is uploaded by the operator.

The laser device used in the experiments is a Rofin-Sinar Laser, model Power Line E-20, maximum power $\mathrm{P}_{\max }=1.77 \mathrm{kVA}$ and maximum current $\mathrm{I}_{\max }=7.7 \mathrm{~A}$, Diode pumped $\mathrm{Nd}$ : YAG laser, pulsed (Q-switch), with wavelength: $1064 \mathrm{~nm}$. The device is integrated into the end of line testing equipment and it is used only for specific families of a product.

The plastic components used in the mechatronic device are molded injected from a polycarbonate (PC), Makrolon 2405, a translucent thermoplastic coated by a paint system from Alexit, hardener mixed with the laser coating, one layer sprayed in a Venjakob painting line $[7,8]$.

The experiments were developed based on the etching of the parts at different timing direct after the painted batch was out of the line. According to the process, the plastic painted parts are oven-dried around 40 minutes at almost 80 degrees Celsius, as is presented in the curve from Figure 3, measured with the Voltcraft - termologger 309, digital, with sensors Tc type $\mathrm{K}$.

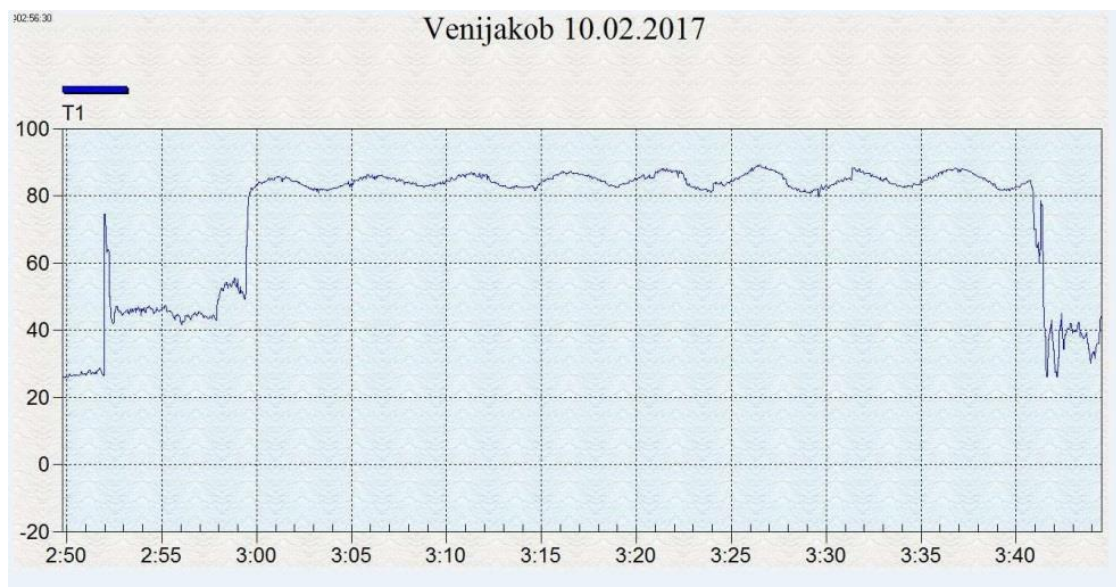

Fig. 3. Drying curve oven Venjakob. 
The number of selected parts for testing was 18 button sets, for each of one experiment out of six have been used 3 button sets, first two sets for testing of the adjustment, and only the last one evaluated and measured.

The time for laser etching was established based on the issues coming from manufacturing in the last half year, and the investigation shows that the most of all parameter changing have been made when the parts arrive in laser between 45 minutes to 3 hours after end of painting line (the parts need to be visually checked after the conveyor and the duration of this operation is around 30-40 minutes). Therefore, the test samples have been sent to laser etching as is presented in Table 1. Must be mentioned that the storage environment is controlled by the sensors and assured by an installation that provides a certain level of humidity and the temperature (according to the requirements from the electronic production in automotive). As can be seen in the table, the humidity as well the temperature has almost no variation.

Table 1. Sampling for testing.

\begin{tabular}{|c|c|c|c|}
\hline \multicolumn{2}{|c|}{ Sampling } & \multicolumn{2}{c|}{ The storage environment } \\
\hline Test No. & $\begin{array}{c}\text { Duration } \\
\text { (minutes) }\end{array}$ & $\begin{array}{c}\text { Humidity } \\
(\%)\end{array}$ & $\begin{array}{c}\text { Temperature } \\
\text { (Celsius) }\end{array}$ \\
\hline T1 & 10 & $43.20 \%$ & 23.8 \\
\hline T2 & 60 & $43.80 \%$ & 23.9 \\
\hline T3 & 120 & $43.50 \%$ & 24.0 \\
\hline T4 & 240 & $43.50 \%$ & 24.0 \\
\hline T5 & 640 & $43.60 \%$ & 24.1 \\
\hline T6 & 1440 & $43.50 \%$ & 23.9 \\
\hline
\end{tabular}

The chosen parameters in analysis from laser equipment to work with are the following: the laser current, the speed, and the pulse width.

Nowadays, the manufacturer is challenged by the large number of parts to be produced, it means that is very important which is the efficiency of each step from the processes, then the reducing of the speed and the pulse width is not a good option because will increase the tact time, reducing number of parts per hour. As a consequence, the speed remains at 1000 $\mathrm{mm} / \mathrm{s}$ and the pulse width at 100 us (microseconds). The study was based visual validation of the part by the quality inspector, and by the laboratory measurements in the 3D scan and $2 \mathrm{D}$ optical equipment. The requirements are established for a clean area after removing the paint, but also the dimension of the symbol width, as is presented in Figure 4, a) and b).

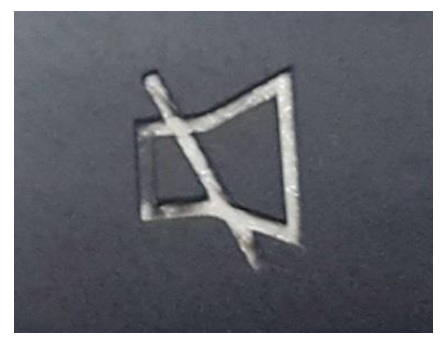

Fig. 4. a) Incomplete removal of the paint.

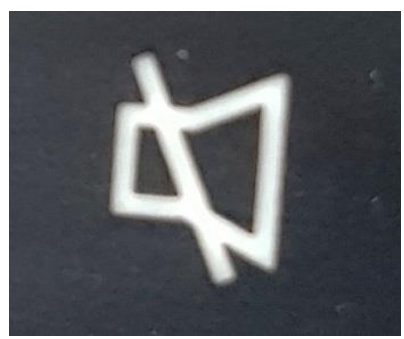

b) Symbol width too big. 
The adjustment of the current was performed in three steps: the first step, based on the experience, the current value was set at one estimated value, and then the part was visually inspected. Based on the result of the inspection, the second step was made an increase between $0.2 \mathrm{~A}$ to $0.6 \mathrm{~A}$, and in the last step usual only fine adjustment, between $0.1 \mathrm{~A}$ to $0.2 \mathrm{~A}$. As the most of all situations, the parts are dry, for the wet parts (direct from the painting line) the current was decreased because of the wrong estimation at the first adjustment (see Table 2).

Table 2. Adjustment of the parameters of laser.

\begin{tabular}{|c|c|c|c|c|}
\hline \multicolumn{2}{|c|}{ Sampling } & Trial 1 & Trial 2 & Trial 3 \\
\hline Test No. & $\begin{array}{c}\text { Duration } \\
\text { (minutes) }\end{array}$ & $\begin{array}{c}\text { Current } \\
\text { (A) }\end{array}$ & $\begin{array}{c}\text { Current } \\
\text { (A) }\end{array}$ & $\begin{array}{c}\text { Current } \\
\text { (A) }\end{array}$ \\
\hline T1 & 10 & 21.0 & 20.5 & 20.1 \\
\hline T2 & 60 & 20.0 & 20.6 & 20.7 \\
\hline T3 & 120 & 20.6 & 20.8 & 21.0 \\
\hline T4 & 240 & 20.8 & 21.0 & 21.1 \\
\hline T5 & 640 & 21.5 & 21.5 & 21.5 \\
\hline T6 & 1440 & 21.5 & 21.5 & 21.5 \\
\hline
\end{tabular}

As the result of the measurements can be observed that the current adjustment for the last tests, T5 and T6, was the same and not needed to be changed from the steps. Also can be notified that risk to produce a part with laser etching non-conform is very big if the parts are wet and delivered immediately after the end of painting line, and still big is the parts arrive in the assembly in less than an hour. And this, because usually the laser is adjusted at the bigger current value which will burn the plastic material and the symbol width will be out of the tolerance (Figure 5).

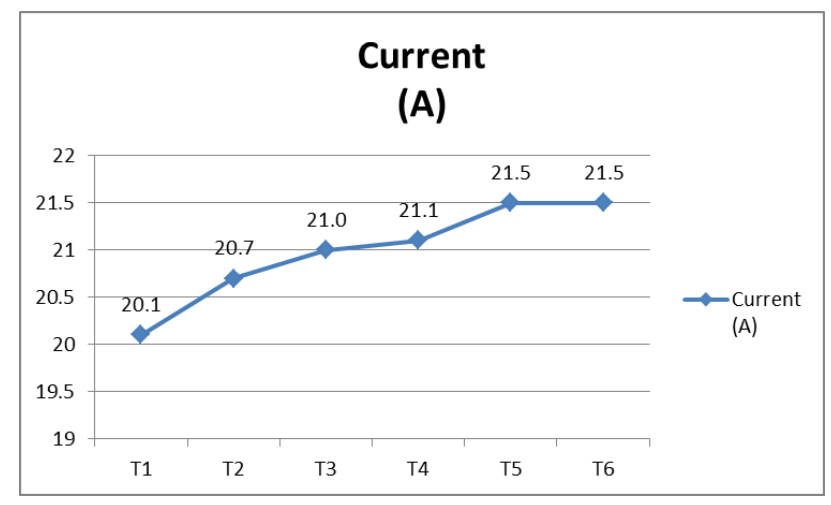

Fig. 5. Graph of laser current variation.

All the parts from the last adjustment were measured in the laboratory in 2D O-Inspect Zeiss equipment. The microscope was programmed to measure the distance between the line 1 and line 2, in fact, the border from the removed paint and the plastic material, as can be seen in Figure 6, a) and b). 


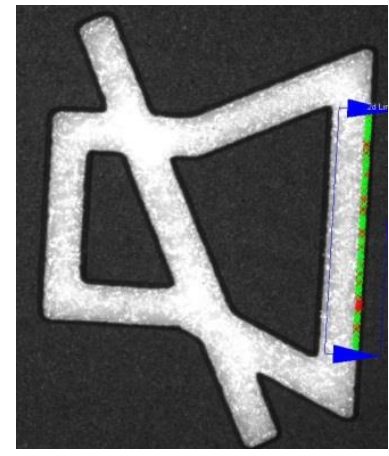

Fig. 6. a) Symbol width programming - line 1 .

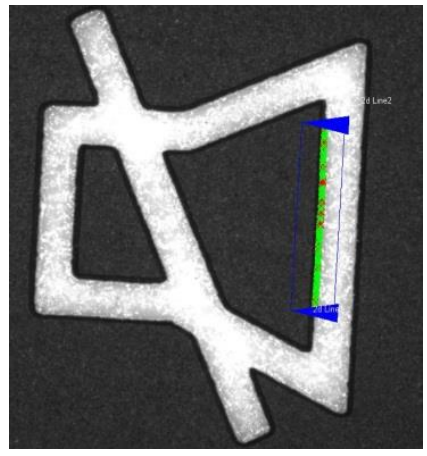

b)Symbol width programming - line 2 .

For instance, in Figure 7, a) and b), can be easily observed that the test T2 had the NOK result of first step adjustment at 20.0 A, and the laser etching was not completely, then in third step the dimension was according with the requirements $(0.4 \mathrm{MM}+/ 0.1 \mathrm{MM})$.

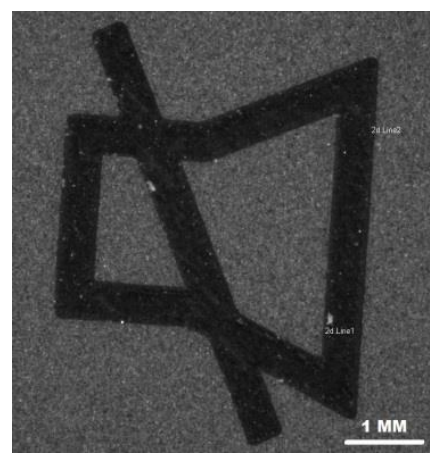

Fig. 7. a) Symbol width $T 2$ step 1.

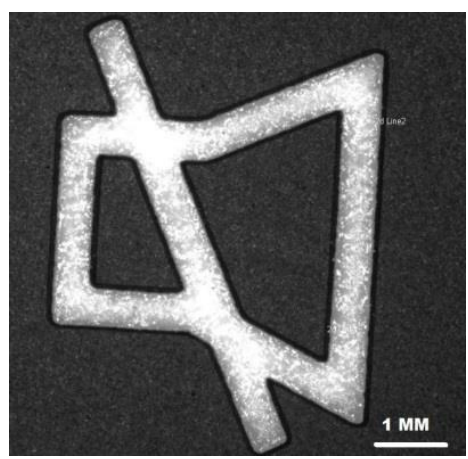

b) Symbol width T2 step 3 .

In order to prove the hypothesis that the current adjustment is enough to be adjusted and as wet the painted parts are, so small the current must be, the depth of laser etching was measured in 3D measuring techniques with ATOS ScanBox - Optical 3D Coordinate Measuring Machine, Series 4, ATOS CORE MV 135. Based on the evaluation of all tests, was observed a variation in an average of the depth around 5 microns if compared the test T1 and test T5 - see Figure 8, a) and b).

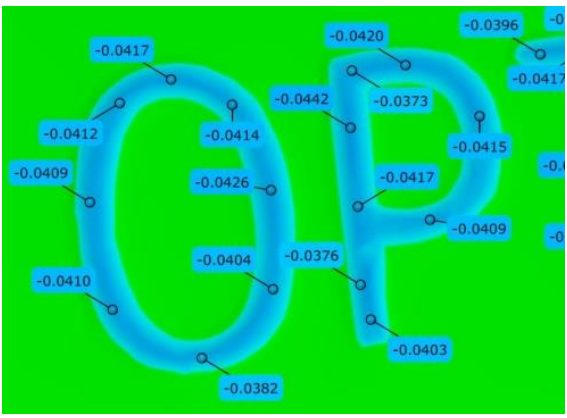

Fig. 8. a) Symbol depth T1 step 3.

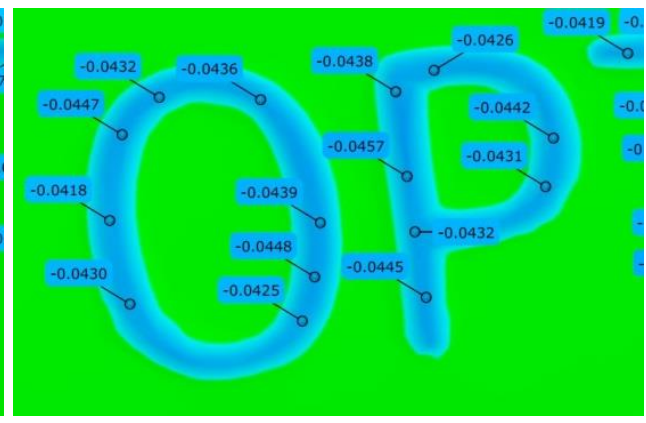

b) Symbol depth T5 step 3 . 


\section{Conclusion and next steps}

The study shows the influence and adjustment of the current at laser etching of painted parts for the situation when the parts are wet or dry. In that way, the process can be developed in such a way to give the signal to the next operation when the parts are delivered directly from the painting area or they are stored in the warehouse. The experiments used the plastic molded injected parts from polycarbonate (PC) coated with a paint system water based and only one layer on the parts.

Similar studies were made of the other pieces of the same plastic material but using the paint system in two layers (from the same provider), the results are not relevant and further tests with more samples will be done.

As a lesson learned, in the time of the studies were observed differences between the lasers etching equipment in regard to the type used, the presented study has been made on Rofin equipment, and the second study on the Foba equipment. More, the life duration of the laser diode for the Rofin equipment was at the beginning, and the life duration of the laser diode from Foba equipment was almost half. Therefore, a study to understand the variation due to changing of the current and the life time of the laser diode is to be made. Also is good to know if an optimal configuration of the parameters such as current, pulse width, speed and line width or other beam parameters could be found by using the design of experiment Taguchi method in order to obtain a higher level of generalization of the research.

\section{References}

1. J. Hecht, Short history of laser development, Optical engineering, 49(9), 091002 (2010)

2. A. H. Rawicz, Theodore Harold Maiman and the invention of Laser, Proc. of SPIE 713802-1 (2008)

3. C. Nitish, B. Sudeep, IJRAP, 2(1), 132-141 (2011)

4. M.C. Rao, Research Journal of Material Sciences, 1(2), 20-24 (2013)

5. J. Dong, X.-S. Liu, C. Peng, Y.-Q. Liu, Z.-Y. Wang, Applied Sciences, 5, 1837-1845 (2015)

6. ***, LASER Light Amplification by the Stimulated Emission of Radiation, https://lasersdbw.larc.nasa.gov/tutorials/laser/ (2017)

7. ***, Venjakob, Ven Spray Perfect, https://www.venjakob.de/en/our-plants/detail/venspray-perfect-17/index.nc (2017)

8. ***, Mankiewicz, Product and markets, Automotive, http://www.mankiewicz.com/english/products-markets/automotive/ (2017) 
